\title{
LAS CARTAS DE PATROCINIO Y SU RECEPCIÓN EN EL DERECHO CHILENO. NOTAS A PROPÓSITO DE UNA SENTENCIA DE LA CORTE SUPREMA
}

\author{
THE COMFORT LETTERS AND ITS RECEPTION IN \\ CHILEAN LAW. NOTES ABOUT A SENTENCE OF THE \\ SUPREME COURT
}

JAIME ALCALDE SILVA*

Prof. de Derecho Privado

P. Universidad Católica de Chile

Santiago - Chile

\section{RESUMEN}

Las cartas de patrocinio, como una forma de garantía atípica en la práctica bancaria chilena, han sido estudiadas por la doctrina en cuanto a su naturaleza y efecto vinculante. Sin embargo, y a diferencia del derecho comparado, los tribunales chilenos no tuvieron ocasión de pronunciarse sobre la fuerza obligatoria de estos documentos hasta hace algunos años (2011). Analizaremos dicha sentencia para determinar cuáles fueron los criterios utilizados en ella, comentando los aspectos más relevantes de la decisión de la Corte Suprema, incluidos aquellos omitidos, y ofreciendo nuestras conclusiones sobre el particular.

Palabras clave: Cartas de patrocinio, garantía (garantía atípica), derecho bancario, jurisprudencia.

*Licenciado en Derecho, Pontificia Universidad Católica de Chile, Abogado. Doctor en Derecho, Universidad de Valencia (España). Profesor asistente de Derecho Privado, Pontificia Universidad Católica de Chile. Correo electrónico jcalcald@uc.cl. Artículo recibido el 2 de agosto de 2017 y aceptado para su publicación el 6 de noviembre de 2017. 


\section{ABSTRACT}

Comfort letters, as a form of atypical guarantee in the Chilean banking practice, have been studied by the doctrine as to its nature and binding effects. However, unlike comparative law, the Chilean courts had no opportunity to rule on the binding force of these documents until a few years ago (2011). We will analyze this judgment to determine which criteria were used in it, commenting on the most relevant aspects of the decision of the Supreme Court, including those omitted, and offering our conclusions on the matter.

Keywords: Comfort letters, guarantee (atypical guarantee), banking law, case law.

\section{INTRODUCCIÓN}

Las cartas de patrocinio tienen ya un dilatado empleo en la práctica bancaria chilena como una forma de garantía atípica. Los textos utilizados son más o menos uniformes y son suficientes para generar en el banco la confianza de que la operación a la que acompañan tendrá un buen resultado por el respaldo que le confiere el prestigio del suscriptor. También la doctrina ha abordado su naturaleza y efecto vinculante. Sin embargo, y a diferencia de lo que ocurre en derecho comparado, nuestros tribunales no habían tenido ocasión de pronunciarse sobre la fuerza obligatoria de estos documentos hasta el juicio que concluyó con la sentencia de la Corte Suprema de 11 de enero de 2011 (rol $\mathrm{n}^{\mathrm{o}}$ 5489-2009), pues otros casos anteriores habían terminado extrajudicialmente o no habían trascendido públicamente. ${ }^{1}$

Por eso conviene analizar esa sentencia y determinar cuáles fueron los criterios utilizados por la Corte para finalmente rechazar la demanda fundada en una carta de patrocinio. Con ese fin, se ofrece primeramente un resumen de los hechos y argumentos invocados por las partes en el juicio y las decisiones

\footnotetext{
${ }^{1}$ En el asunto resuelto merced a la sentencia del TDLC de 25 de octubre de 2013 (núm. 132/2013) también hubo un pronunciamiento sobre las cartas de patrocinio y su fuerza vinculante, especialmente en los informes en derecho evacuados por los profesores Arturo Prado Puga y Bruno Caprile Biermann. Cabe hacer presente que el primero fue director de la memoria de PRADO (1994) y el segundo se había ocupado del valor de estos documentos en CAPrile Biermann, Bruno, "La reforma al derecho de las cauciones en Francia: perspectivas para un devenir en Chile", en Guzmán Brito, A. (editor), Estudios de derecho civil III, Legal Publishing, Santiago, 2008, pp. 538-540, con referencia a la reforma francesa del derecho de garantías ocurrida en 2006 (v. la nota 46).
} 
de los distintos tribunales (II), para pasar después al comentario de los aspectos más relevantes de la decisión de la Corte Suprema, incluidos aquellos preteridos (III). Cierra el trabajo un pequeño cuerpo de conclusiones (IV).

\section{LA CUESTIÓN DISCUTIDA}

El banco BICE dedujo demanda ordinaria de cobro de pesos ante el $21^{\text {er }}$ Juzgado Civil de Santiago en contra de las sociedades Inmobiliaria e Inversiones Pellín Limitada, Inversiones Las Cepas Limitada, Inversiones Los Nostros Limitada, Inversiones La Espalderas Limitada, y Vergara Rourke y Compañía Limitada. En ella solicitaba que se condenase a cada una de las demandadas, en igual proporción, a pagar las deudas directas e indirectas a que se encontraba obligada la Sociedad de Inversiones Villarrica Limitada, que ascendían a $32.667,1577$ UF y 374.535 .784 pesos chilenos (CLP), respectivamente, más los intereses pactados y las costas de la causa.

El banco fundaba su demanda en la suscripción de una carta datada el 18 de octubre de 1996, por la cual las demandadas se obligaron a pagar, en caso de incumplimiento de las obligaciones y compromisos que dicho instrumento contenía, todas las deudas directas e indirectas que la Sociedad de Inversiones Villarrica Limitada mantuviese con aquella institución. Sucedió que se infringieron los compromisos previstos en los números $4^{\circ}$ y $8^{\circ}$ de ese acuerdo, que consistían en que la sociedad recién individualizada no cedería ni enajenaría sin previo aviso al banco los activos fijos o financieros que representasen más del 50\% de su activo total. En los meses de mayo y julio de 1998 Inversiones Villarrica había enajenado sus activos en esa proporción, de lo que sólo dio cuenta al banco el día 31 de ese último mes, reconociendo así las enajenaciones ya realizadas, sin haber obtenido de su parte la autorización previa a que se encontraba obligada y respecto de las cuales dicha entidad tenía derecho a oponerse. Este incumplimiento justificaba que el banco se dirigiese contra las sociedades demandadas, quienes debían pagar el total de las deudas que se encontraren pendientes a aquella fecha (sin perjuicio de su ulterior derecho de repetición). A juicio del banco, los activos que habían sido enajenados sin su autorización fueron considerados como un elemento esencial a la hora de otorgar los créditos cuyo cobro ahora se demandaba, y constituyeron el motivo por el cual las sociedades demandadas, en calidad de únicas socias de Inversiones Villarrica Limitada, suscribieron la carta de compromiso.

Como consecuencia de ese incumplimiento, las sociedades demandadas venían obligadas al pago de las deudas directas e indirectas que mantenía 
Inversiones Villarrica para con el banco BICE. La primera provenía de un contrato de mutuo suscrito con Inversiones Villarrica el 25 de octubre de 1996, por un monto original equivalente a $88.847,2101 \mathrm{UF}$, de las cuales adeudaba aún $32.667,1577$ UF, más los intereses pactados. Dicha suma se encontraba por entonces en disputa ante otro tribunal. La segunda deuda estaba representada por tres pagarés suscritos por Inmobiliaria Ginebra, en que figura como avalista de todos ellos Inversiones Villarrica por un total de 374.535.784 CLP, la que también se encontraba en ese momento en proceso judicial de cobro en contra de las obligadas directas mediante una acción ejecutiva.

Al contestar la demanda, Inversiones Las Espalderas solicitó su íntegro rechazo, dado que no existía título válido que permitiese la condena de las sociedades demandadas. En su parecer, aquel que invocaba el banco demandante era una simple declaración unilateral de voluntad, que no daba cuenta de la existencia de un acuerdo previo entre las distintas partes, esto es, entre los declarantes y el banco y, por consiguiente, no generaba obligaciones para ninguna de ellas. Además, el título del banco demandante se refería exclusivamente a actos relacionados con Inversiones Villarrica, una persona jurídica diversa, sin imponer ni especificar ninguna obligación respecto de las sociedades suscriptoras de la carta. Agregaba que el banco demandante no podía pretender que se reconociesen efectos jurídicos al documento en cuestión, porque éste carecía de causa, al no existir reciprocidad entre las prestaciones de las partes, sin que se pudiese considerar que ella daba cuenta de una mera liberalidad, dado que, de ser así, el acto se trasformaría en una donación, sin cumplir con las exigencias que la ley impone para éstas (principalmente, la insinuación y el pago del impuesto exigido por la Ley 16.271). En cualquier caso, las obligaciones que el banco reputaba incumplidas no correspondían cumplirlas a su parte, sino que recaían exclusivamente en Inversiones Villarrica, por lo que, al no existir obligación, no puede haber infracción ni incumplimiento, a lo que añadía que, en todo caso, era el banco el que debía soportar el peso de probar la existencia de un acto doloso o culpable. Desconocía, por último, la existencia y exigibilidad de las obligaciones que se reclamaban.

La demandada Vergara Rourke y Compañía Limitada, además de reiterar las alegaciones formuladas por Inversiones Las Espalderas sobre la inexistencia de una obligación a su respecto, negó en su contestación la existencia de las deudas que reclamaba el banco demandante. Sostuvo que aquellas denominadas directas fueron contraídas por una persona jurídica distinta de Inversiones Villarrica, aunque formalmente ésta aparezca como deudora, toda vez que el crédito fue realmente conferido a Inmobiliaria Ginebra S.A., sociedad de la 
cual Inversiones Villarrica Limitada era accionista al tiempo de la operación. Sin embargo, dada la cuantía del crédito solicitado por Inversiones Ginebra S.A., fue el propio banco quien propuso que parte de él fuera otorgado a Inversiones Villarrica Limitada, sociedad esta última que con posterioridad traspasó los fondos a la referida inmobiliaria. La operación comportaba, a su juicio, simulación, de manera que el contrato de mutuo adolecía de objeto ilícito por infracción a las normas de orden público que regulan la actividad financiera.

Respecto de las deudas indirectas provenientes de los pagarés, esta demandada añadió que ellas se encontraban en disputa ante otro tribunal mediante acción ejecutiva, proceso en el que se discutía el monto exacto de la obligación, puesto que existían diversas imputaciones al crédito realizadas por Inversiones Villarrica Limitada. A lo que se agregaba la existencia de un nuevo juicio, en el cual el banco se adjudicó un inmueble perteneciente a la sociedad señalada en pago de las mismas obligaciones que ahora cobraba.

Como fuere, esta demandada invocó la ausencia de incumplimiento de las obligaciones que emanan de la carta de compromiso por parte del presunto deudor, alegando al respecto la existencia de una estafa que propició la venta de Financiera Condell S.A., que representaba más del 50\% de los activos fijos de Inversiones Villarrica Limitada. ${ }^{2}$ La referida venta fue ampliamente publicitada desde octubre de 1997 hasta junio de 1998, de manera tal que el banco siempre estuvo en conocimiento de la operación por tratarse de hechos públicos y notorios, tanto que fue candidato a llevar a cabo el proceso de valorización de la compañía. Incluso, el mandatario de Inversiones Villarrica Limitada consultó personalmente al gerente de administración y finanzas del banco demandante respecto del interés de la institución en adquirir la financiera, sin perjuicio de los diversos contactos entre ambos para informar

\footnotetext{
${ }^{2}$ La Financiera Condell S.A. fue constituida por escritura pública de 30 de junio de 1976 otorgada en la Notaría de don Rafael Zaldívar Díaz, y su existencia permitida merced a la Resolución núm. 81/1976 de la Superintendencia de Bancos e Instituciones Financieras. La Resolución núm. 112/1976 autorizó su funcionamiento y sus operaciones comenzaron el 10 de diciembre de 1976. El 9 de junio de 1998, Corpbanca (hasta el año anterior Banco Concepción) adquirió el 99,99\% de las acciones de Financiera Condell S.A, y el 13 de noviembre de ese año la Superintendencia de Bancos e Instituciones Financieras autorizó la denominada "fusión operativa" entre ambas entidades, la que consistió en traspasar la cartera de los créditos de consumo de la División Corfinsa desde el banco a la financiera recién adquirida. Finalmente, con fecha 5 de agosto de 1999, el mentado banco efectuó una publicación en la prensa comunicando que el 27 de julio de ese año había adquirido 3.400 acciones de Financiera Condell S.A. que eran de propiedad de Corp Factoring S.A. De esa manera, se produjo la disolución de Financiera Condell S.A. al reunirse en manos de Corpbanca la totalidad de las acciones emitidas por dicha financiera, habiéndose incorporado la totalidad de sus activos, pasivos y patrimonio a dicho banco, quien pasó a sucederlo en todos sus derechos y obligaciones. En la actualidad, Corpbanca opera el Banco Condell, que ofrece créditos de consumo, convenios, depósitos a plazo y seguros.
} 
sobre el proceso de venta de la misma. ${ }^{3}$ Por consiguiente, y puesto que el banco siempre estuvo en conocimiento de la operación de venta, según el tenor literal de la carta de compromiso, cabía tener por cumplida la obligación de comunicarle la enajenación de más de un 50\% del activo. Obligación que, por lo demás, adolecía de un vicio de nulidad absoluta por impedir la libre circulación de los bienes, con afectación del orden público económico.

En todo caso, aun cuando hubiese existido ese incumplimiento, éste no era imputable a las suscriptoras de la carta de patrocinio, pues la enajenación se debió a un caso fortuito o fuerza mayor derivado de los hechos que rodearon la venta de la Financiera Condell.

Por su parte, Inmobiliaria e Inversiones El Pellín Limitada e Inversiones Las Cepas Limitada contestaron la demanda reiterando la ausencia de vinculación entre las deudas indirectas que se cobraban con la sociedad Inversiones Villarrica, quien aparece como obligada a las mismas, refiriendo además las excepciones que dicha sociedad opuso en el juicio ejecutivo que el banco seguía en su contra, donde sostuvieron se estableció la simulación denunciada. Sobre este punto, agregaron que el banco perseguía el cobro de las deudas mediante procesos diversos, que pueden implicar un doble pago y, por ende, un enriquecimiento sin causa. Por último, ambas demandadas reiteraron las defensas ya mencionadas por las otras sociedades codemandadas.

El tribunal de primera instancia rechazó la demanda en todas sus partes. El fallo se fundaba en el carácter taxativo de la enumeración de las fuentes de las obligaciones que hace el artículo $1437 \mathrm{CC}$, estableciendo que el título que invocaba el banco demandante, constituido por la carta de fecha 18 de octubre de 1996, comportaba una declaración unilateral de voluntad mediante la cual las demandadas se habían obligado a dar cumplimiento a determinados compromisos, cuyo incumplimiento hacía exigible el deber de satisfacer tanto las deudas directas como indirectas de otra sociedad.

Respecto de la posibilidad de que la declaración unilateral de voluntad

\footnotetext{
${ }^{3}$ Las sociedades financieras estaban tratadas en el Título XIV de la Ley General de Bancos, el que fue derogado por el artículo $3^{\circ}$ de la Ley 20.190. Aunque entre ellas y los bancos existían muchas semejanzas, también había algunas diferencias. Fuera del público al que servían, las principales consistían en que las financieras requerían de un capital menor para su constitución (sólo 400.000 unidades de fomento) y que no podían ofrecer cuentas corrientes ni realizar operaciones en monedas extranjeras o de comercio exterior. La Ley 20.190 vino, con todo, a constatar una realidad del sector bancario al comienzo de este siglo, porque ya entonces no existían financieras en operación: la mayoría de ellas había sido absorbida por los bancos, dado que eran directa competencia de sus divisiones de crédito de consumo, y el resto había cesado en sus operaciones. En parte, la función social de las financieras es cumplida hoy por las cooperativas de ahorro y crédito.
} 
constituyese fuente de obligaciones $\mathrm{y}$, por ende, transformase al declarante en deudor, sin intervención del acreedor en la generación de la obligación, el $21^{\circ}$ Juzgado Civil de Santiago concluyó que una declaración obligatoria exige la intervención de dos sujetos (acreedor y deudor), de manera que la voluntad única de uno de ellos no puede hacer nacer una obligación, salvo en los casos en que la ley expresamente admite la declaración unilateral de voluntad como fuente de obligaciones. ${ }^{4}$ De lo anterior se sigue que la promesa unilateral no constituye en general un instrumento de autonomía privada de carácter obligatorio, salvo en aquellos casos excepcionales que se encuentran especialmente tipificados por la ley, lo que no ocurre en el caso planteado. Esto impide que pueda ejercerse una acción de condena en contra de las sociedades demandadas, puesto que el contenido de la carta de 18 de octubre de 1996 sólo establecía una mera declaración, que cuanto más podía ser considerada como una expresión de buena voluntad, un compromiso de honor o una obligación de mero carácter moral, carente de obligatoriedad jurídica.

Apelada esta sentencia, la Corte de Apelaciones de Santiago confirmó su decisión por sentencia de 14 de mayo de 2009. Contra esta última, el banco demandante interpuso recurso de casación en el fondo fundado en la infracción del artículo 1437 CC, que se habría materializado al calificar erróneamente el documento suscrito el 18 de octubre de 1996, que revestía el carácter de una carta de compromiso o comfort letter y, por consiguiente, no era vinculante para las sociedades suscriptoras, como una mera declaración unilateral de voluntad, sin alcance obligatorio. Para el banco, la carta constituía en realidad la aceptación de una oferta o propuesta hecha por él consistente en el otorgamiento de una garantía, de manera que su suscripción no comportaba la existencia de una declaración de voluntad, sino de un contrato unilateral.

Por sentencia de 11 de enero de 2011, la Corte Suprema rechazó el mentado recurso por estimar que el error de derecho invocado, aun cuando efectivamente se habría producido, no tuvo incidencia en lo dispositivo del fallo. El razonamiento de la Corte se fundó en que, con el mérito de los antecedentes que obraban en el proceso y que fueron establecidos por los jueces del fondo, no se lograba vislumbrar que se hubiesen verificado los presupuestos que hacían procedente la acción de cobro de pesos deducida por el banco recurrente, en

\footnotetext{
${ }^{4}$ La literatura especializada suele mencionar dos situaciones donde la ley consagra expresamente la declaración unilateral de voluntad como fuente de las obligaciones: (i) la oferta con plazo de espera (artículo 99, C. Com.) y (ii) la promesa pública de recompensa (artículo 632 II CC). Véase, por ejemplo, Peñailillo Arévalo, Daniel, Obligaciones. Teoría general y clasificaciones. La resolución por incumplimiento, Editorial Jurídica de Chile, Santiago, 2003, pp. 137-138.
} 
especial la naturaleza y montos de los perjuicios, los cuales no se reservaron para la fase de cumplimiento o ejecución del fallo declarativo. De esta manera, y aunque la Corte no concordase con la argumentación que sustentaba el fallo recurrido, estimó que de todos modos había de llegar a la misma conclusión, esto es, que la demanda interpuesta no podía prosperar por no reunirse los presupuestos que la justificaban.

\section{COMENTARIOS SOBRE EL PARTICULAR}

El caso recién descrito presenta varias cuestiones de interés relacionadas con el alcance vinculante de la voluntad y la configuración de garantías atípicas a través de ella. La argumentación del banco demandante y de las sociedades demandadas bien se puede resumir en la discusión en torno a la calificación jurídica que revestía el documento suscrito por estas últimas con fecha 18 de octubre de 1996. Según el banco, ese instrumento era una carta de patrocinio (denominada ahí "carta de compromiso" o comfort letter) que imponía obligaciones jurídicas a las sociedades suscriptoras y, por tanto, permitía reclamar judicialmente de su incumplimiento. La razón era que ella daba lugar a la aceptación de una oferta o propuesta hecha por el banco respecto del otorgamiento de una garantía, que fue aceptada por las sociedades suscriptoras y dio origen a un contrato unilateral. Para las sociedades demandadas, por el contrario, dicha carta carecía de eficacia vinculante y sólo comportaba una declaración unilateral de voluntad carente de causa, la que quedaba dentro del plano de los compromisos morales.

Conviene así, ante todo, referir el tratamiento que han tenido las cartas de patrocinio en la práctica bancaria y las consideraciones que en torno a ellas ha hecho la literatura científica chilena (1). Esto servirá de preámbulo al análisis

\footnotetext{
${ }^{5}$ Aquí se prefiere el término "carta de patrocinio" por las razones dadas en AlCALDE SiLVA, Jaime, "Las cartas de patrocinio: situación en Chile y en el derecho comparado", en: Tapia Rodríguez, M.; Gaitán Martínez, José A.; Juricic Cerda, Daniel; Salah Abusleme, María A.; Mantilla Espinosa, Fabricio (directores), Estudios sobre garantías reales y personales. Libro homenaje al Profesor Manuel Somarriva Undurraga, Editorial Jurídica de Chile, Santiago, 2009, T. I, pp. 239-242. Tal fue también la denominación empleada tempranamente por Prado Lavín, Cristóbal, La carta de patrocinio, Memoria para optar al grado de Licenciado en Ciencias Jurídicas y Sociales, Universidad de Chile. Santiago, 1994, que es el primer trabajo dedicado en Chile a esta materia. Con todo, en la práctica forense se suele hablar de comfort letters. La denominación "carta de resguardo», que se utiliza a veces como sinónimo en derecho comparado, tiene en Chile un sentido propio: los instrumentos que "se dan, por lo general, para efectos de alzamiento de gravámenes, ya sea que se trate de hipotecas o de prendas, o bien que tengan su origen en un mandato de comisiones de confianza" (SUPERINTENDENCIA DE BANCOS
} 
del documento de 18 de octubre de 1996 que dio origen al juicio antes referido (2). Fuera quedan otras cuestiones accesorias que, pese a su interés, no fueron consideradas por la Sentencia de la Corte Suprema de 11 de enero de 2011.

\section{La recepción de las cartas de patrocinio en la práctica y la doctrina chilenas}

Las cartas de patrocinio son una forma de garantía propia de las relaciones comerciales nacida de los usos bancarios internacionales y estrechamente relacionado con el financiamiento de los grupos empresariales, aunque su versatilidad rebase con creces tal ámbito de aplicación. ${ }^{6}$ En nuestro país se acostumbra a definir estos documentos como una carta emitida por el o los accionistas de una sociedad, a través de la cual se suscribe un compromiso para mantener una participación accionaria o la dirección de la sociedad, o bien para apoyar financieramente al deudor principal en caso que enfrente problemas de pago. ${ }^{7}$ De forma más general, cabe decir que ellas son una declaración por medio de la cual una persona (el patrocinador) asegura a otra (el acreedor o destinatario) que las condiciones que se tienen en cuenta para concluir una determinada operación con un tercero (el patrocinado) permanecerán en el tiempo, formando en aquél la expectativa de que dicha operación será satisfactoriamente cumplida, incluso merced a la intervención del otorgante. ${ }^{8}$

\footnotetext{
E Instituciones Financieras, Recopilación actualizada de normas, Capítulo 8-12).

${ }^{6}$ Véase, por ejemplo, Diago Diago, Ma. del Pilar, Las cartas de patrocinio en los negocios internacionales. Estudio jurídico, Thomson Reuters/Aranzadi, Cizur Menor, 2012.
}

${ }^{7}$ Banco Santander (editores), Manual de riesgos (Capítulo 3: Manejo y control de garantías, Tema: Alcance de riesgos sobre distintos tipos de garantías), edición interna, Santiago, 2002, p. 43. Prado, cit. (n. 5), p. 15, define la carta de patrocinio como "un documento o declaración escrita, exenta de formalidad, emitida por una empresa madre de un grupo de empresas, situada usualmente en otro país, que busca que un banco o grupo de bancos otorguen un crédito a una sociedad filial, relacionada con la sociedad madre, y de una relativa debilidad patrimonial". Por su parte, Serrano Herrera, Claudia, "La legitimación para el pago de un tercero", Revista de Derecho de la Pontificia Universidad Católica de Valparaíso, 2011, Vol. XXXVII, p. 178, señala que ellas "constituyen una garantía del tráfico usualmente utilizadas en la práctica bancaria y darán origen a responsabilidad subsidiaria del patrocinador cuando éste garantice o se comprometa para con un destinatario, acreedor de la obligación principal, a cumplir o indemnizar en caso de incumplimiento del patrocinado o deudor principal". Para Chaparro NAVARRete, Patricio, “Acerca de las operaciones bancarias y notas sobre 'securitización' o titulización de créditos (revisitada); bonos subordinados; 'comfort letters' y cartas de crédito 'standby", Gaceta Jurídica, 2001, n 248, p. 107, el concepto es más restringido, y se circunscribe a "las cartas enviadas por una empresa o sociedad domiciliada en el extranjero, por medio de las cuales respaldan o resguardan las obligaciones contraídas por sus sucursales o filiales en Chile".

${ }^{8}$ Alcalde Silva, Jaime, Las cartas de patrocinio. Criterios dogmáticos para su aplicación en Chile, Abeledo Perrot - Legal Publishing, Santiago, 2010, p. 13. En el mismo sentido, BARAona GonzÁlez, Jorge, "La promesa en el Código Civil", en Elorriaga De Bonis, F. (coord.), Estudios de Derecho civil 
Aunque su utilización en la práctica bancaria es anterior (como demuestra la fecha de suscripción de aquella que motiva este comentario), las cartas de patrocinio se hicieron popularmente conocidas en Chile por las dificultades económicas que atravesó a mediados de la década pasada la Universidad de la República. Los problemas de insolvencia de esta universidad derivados de la alta morosidad de sus alumnos llevaron al Banco de Chile a intentar la ejecución de una carta de patrocinio. Esta carta había sido suscrita el 30 de mayo de 2006 por el Club de la República (institución que representa patrimonialmente a la Gran Logia de Chile), cuyo directorio había aprobado su emisión en una sesión del día anterior, para garantizar una operación de leaseback que emprendería la universidad por un monto de 5.000.000 USD, con lo que se esperaba hacer frente a la deuda con el Banco del Desarrollo por la garantía solidaria que aquella había asumido respecto de los alumnos con crédito CORFO. En esencia, dicha carta implicaba dos compromisos: el primero era que no se reformarían los estatutos de la universidad para que personas ajenas a la masonería adquiriesen participación en su propiedad, y el segundo que, en el evento que la universidad no contase con los recursos para cumplir con el pago del crédito, la Gran Logia de Chile se comprometía a proporcionar los recursos necesarios mediante aportes de capital o préstamos subordinados, asegurando de esta manera el cumplimiento oportuno y total de las obligaciones impagadas de esa institución. El conflicto suscitado por el deseo del banco de ejecutar la carta significó la expulsión del entonces rector, Jorge Carvajal Muñoz, y la posterior restructuración de la universidad, cuyos problemas han continuado hasta el presente. ${ }^{9}$ Otro caso de gran importancia pública también llevaba envuelto una carta de patrocinio, pero no tuvo en la época mayor cobertura por parte de los medios de comunicación debido a los intereses del país que estaban comprometidos. ${ }^{10}$

VII, Thomson Reuters, Santiago, 2012, p. 376.

9 Véase las referencias en AlCALDE, cit. (n. 8), p. 15.

${ }^{10}$ Se trató de un suceso que pudo haber implicado la bancarrota del Estado chileno. El lunes 10 de marzo de 2003 comenzó la huida de inversionistas desde los fondos mutuos, que terminaría con el retiro de casi dos mil millones de dólares estadounidenses de una cartera total de siete mil millones a raíz del escándalo financiero de INVERLINK, que involucraba la adquisición mediante sobornos de información privilegiada de parte del Banco Central de Chile. Los tenedores de bonos soberanos chilenos se habían decantado por la alternativa de dar aplicación a la cláusula de cross-default, vale decir, de vincular ese incumplimiento con otros préstamos, lo que hubiera provocado la insolvencia del Estado chileno. Frente a esto, el Presidente Ricardo Lagos quería el otorgamiento de una boleta de garantía que asegurase el pago en caso de que los tribunales fueran adversos a los inversionistas. Después de las conversaciones entre Hernán Somerville (Asociación de Bancos) y Juan Claro (Confederación de la Producción y el Comercio) con el entonces Ministro de Hacienda Nicolás 
La mayoría de los bancos tienen un protocolo establecido respecto del régimen aplicable a las cartas de patrocinio. Por lo general suelen aconsejar su utilización en algunos de los siguientes casos: (i) cuando se trata de una empresa bien calificada desde el punto de vista del riesgo, pero existen algunas dudas acerca de la continuidad de alguna de sus variables actuales (por ejemplo, su administración, la participación accionaria de un determinado accionista, su volumen de negocios, etcétera); y (ii) cuando la viabilidad de una empresa depende en gran medida del apoyo que le sigan prestando sus socios o, eventualmente, las distintas instancias del grupo empresarial al que pertenece, especialmente en los casos de operaciones con personas relacionadas y que, por su monto, comprometen en parte la solvencia futura de la sociedad (artículo 90 LSA). Aunque sea lo usual, no es necesario que entre el patrocinador y el deudor patrocinado exista relación societaria alguna ni menos dependencia económica. ${ }^{11}$ De igual forma, cuando el patrocinador declara que tiene la titularidad plena o al menos una de carácter relevante en la sociedad patrocinada tampoco está queriendo con ello afirmar que es administrador de hecho de esta última, pues su declaración se limita a expresar una realidad y no las consecuencias jurídicas que ella tiene respecto del dominio fáctico de la compañía o de la confianza que le generan sus administradores. Cuanto más, tal carácter se seguirá de la participación accionaria que ostenta el patrocinador (artículo $97 \mathrm{LMV}$ ), sin que la carta añada nada sobre este punto. ${ }^{12}$

Las cartas de patrocinio comportan, empero, una clase de garantía que se utiliza en períodos de estabilidad o bonanza. El deterioro del entorno económico trae como consecuencia un incremento en el riesgo de los clientes de la banca, lo que redunda en que las entidades financieras aumenten o endurezcan sus condiciones para el otorgamiento de préstamos a personas naturales y jurídicas. Esto significa que, ante escenarios difíciles para el mercado, los créditos más riesgosos deberán pagar una tasa de interés mayor y, además, que se impondrá a quienes desean solicitar un préstamo ciertos requerimientos adicionales de garantías (siempre típicas o, al menos, de ejecutoriedad asegurada) o la

\footnotetext{
Eyzaguirre, se convino la sustitución de dicha boleta por una carta de patrocinio.

${ }^{11}$ Álvarez Lata, Natalia, "Sentencia de 18 de marzo de 2009: Carta de patrocinio fuerte. Asunción de compromisos claros e inequívocos por la patrocinante en caso de impago de la prestataria", Cuadernos Civitas de Jurisprudencia Civil, 2009, nº 81, p. 1465.

${ }^{12}$ Carrasco Perera, Ángel, "Sentencia de 30 junio 2005: Cartas de patrocinio. Obligaciones resultantes de las declaraciones de titularidad sobre el capital de la filial y de apoyo financiero en caso de insolvencia”, Cuadernos Civitas de Jurisprudencia Civil, 2006, nº 71, p. 907.
} 
sujeción a condiciones contractuales particulares expresadas bajo cláusulas restrictivas (conocidas generales como convenants). ${ }^{13}$

Frente a la alternativa de recibir una carta de patrocinio en reemplazo de otra garantía, los bancos prefieren los formularios que tienen preparados y no admiten más que pequeñas variaciones de parte de quien las suscribirá. ${ }^{14}$ Esta práctica hace que sea importante la calificación final del documento, pues por su forma de extensión puede comportar un contrato de adhesión (artículo $1^{\circ}$ LPDC) y, como tal, contener declaraciones que se consideren abusivas (artículo 16 LPDC). En este sentido conviene recordar que parte de la normativa de protección a los derechos de los consumidores se aplica a las micro y pequeñas empresas (artículo $9^{\circ}$ de la Ley 20.416), como ocurre con las reglas de equidad en las estipulaciones y en el cumplimiento de los contratos de adhesión (Título II, Párrafo $4^{\circ}$ LPDC). Aunque no sea usual que las cartas de patrocinio se otorguen por esta clase de empresas, sobre todo dado que el carácter de micro y pequeña empresa está dado por el volumen de los ingresos anuales (artículo $1^{\circ}$ de la Ley 20.416), la posibilidad de que ello ocurra no se debe descartar de plano. Como fuere, y según muestran los hechos, las cartas de patrocinio suelen ser instrumentos que tienen asociada una baja tasa de conflictos.

En caso de que sea el cliente quien remita u ofrezca una carta de patrocinio de un tercero como resguardo de la operación que emprende, su aceptación queda sujeta a la opinión favorable de la fiscalía del banco. Ahí se suele revisar la información de la misma forma como se hace con un pagaré: identificación completa y clara de la persona que asume el compromiso, verificación de poderes de los representantes de una sociedad, existencia de las declaraciones usuales, solvencia del patrocinado y del patrocinador, etcétera (artículos $1^{\circ} \mathrm{y}$ 102 de la Ley 18.092). ${ }^{15}$

Respecto de las cartas de patrocinio emitidas en el exterior, su aceptación queda sujeta al cumplimiento de al menos los siguientes requisitos:

\footnotetext{
${ }^{13}$ Estas cláusulas se definen como un acuerdo entre acreedor y deudor dentro de un contrato de financiación, que considera tanto el debido resguardo para el cobro del crédito como el debido cumplimiento de esos resguardos basados en el plan de negocios y en las proyecciones del obligado.

${ }^{14} \mathrm{El}$ autor ha podido consultar modelos de cartas de patrocinio preparados por los siguientes bancos: Banco de Chile, Banco Santander, BICE, BCI, Banco del Estado de Chile y Banco Security. En general, es desde ellos de donde se extrae una tipología de declaraciones sistematizadas por la doctrina. Véase, por ejemplo, Атті, A., "Nouve modelli di lettere di patronage", Contratto e impresa, 1985, n 3, pp. 973-976, y Bellis, Marc; CoIPel, Michel; Le Brün, Jean; Poullet, Yves; Van Wymeersch, Charles, Les lettres de patronage, FEDUCI - Broche, París, 1984.

${ }^{15}$ En el mismo sentido, para el derecho colombiano, GArCía VÁsquez, Diego, "Garantías independientes y cartas de patrocinio: las mejores alternativas para el comercio internacional”,Revist@e-Mercatoria (U. Externado Colombia) 2006, 5-1, p. 13.
} 
(i) Que en la carta se asuma de modo claro y directo la «responsabilidad» en ciertas deudas contraídas por la sociedad patrocinada. Este primer requisito se refiere a la identificación precisa de quién es la persona que asume la «responsabilidad» por las deudas sociales, o que se compromete a no modificar su participación accionaria dentro de una determinada sociedad, sin que ello importe que ese compromiso trascienda en principio más allá de la relación de confianza que existe entre el emisor de la carta y el banco. ${ }^{16}$ De esto se sigue que estas cartas no pueden ser calificadas sin más como una fianza (artículo $2335 \mathrm{CC}$ ), por la cual una persona natural o jurídica extranjera se compromete a cumplir subsidiariamente las obligaciones asumidas por la sociedad chilena que se patrocina. Tal existirá si el patrocinador se obliga a pagar el crédito de todos modos aunque el patrocinador no se halle en condiciones de hacerlo. ${ }^{17} \mathrm{La}$ exigencia que se comenta atiende, entonces, sólo a la forma de comprobar la regularidad externa de la carta de patrocinio que se emite y, en especial, a precisar su objeto (artículo 1461 CC). El carácter vinculante dependerá de su posterior calificación e interpretación, pero también de la ley de fondo aplicable (artículo $16 \mathrm{CC}) .^{18}$

(ii) Que en la carta se hayan cumplido ciertas solemnidades que garanticen la veracidad de las declaraciones. El principio general en esta materia es que la forma de un instrumento se rige por la ley del país donde es otorgado (artículo $17 \mathrm{CC}$ ), sin perjuicio de que su autenticidad se pruebe en otro país de acuerdo con las reglas que su ordenamiento señale. ${ }^{19}$ Como estas garantías se otorgan casi invariablemente en instrumento privado, su autenticidad se deberá hacer constar por ciertos hechos que rodeen su emisión y que permitan demostrar que verdaderamente se trata de un documento suscrito por el patrocinador. Así ocurrirá, por ejemplo, si la carta se otorga en un papel que lleva el membrete del patrocinador o del grupo empresarial al que pertenece, si en ella la firma es manuscrita y ha sido reconocida o se trata de alguna modalidad equivalente a la firma electrónica (Ley 19.799), si el documento ha sido protocolizado

\footnotetext{
${ }^{16}$ Véase Elizalde Ibarbia, Francisco, El contenido del contrato, Thomson Reuters/Aranzadi, Cizur Menor, 2015, pp. 311-330, donde se analiza extensamente la confianza como fuente del contenido contractual.

${ }^{17}$ Carrasco, cit. (n. 12), pp. 910-911.

${ }^{18}$ AlCalde, Las cartas de patrocinio, cit. (n. 8), p. 114, y Prado, cit. (n. 5), pp. 9-10.

${ }^{19}$ En Chile, el artículo 345 CPC y ahora la apostilla introducida por la Convención de la Haya de Derecho Internacional Privado atañen sólo a la autenticidad de los instrumentos públicos otorgados en el extranjero.
} 
o, al menos, las firmas autorizadas por un notario, etcétera. ${ }^{20}$ Por tratarse de instrumentos privados, el valor final de una carta de patrocinio estará dada por el reconocimiento que de ellas se haga en juicio (artículo 346 CPC). Reconocida por el suscriptor, ella hace plena fe contra éste tanto en lo enunciativo como en lo dispositivo (artículos 1700, 1702 y 1706 CC).

Como fuere, la doctrina chilena se ha pronunciado de forma dividida sobre el carácter vinculante de las cartas de patrocinio. Para un primer grupo, ellas sólo constituyen declaraciones cuya observancia queda entregada al honor del patrocinador. ${ }^{21} \mathrm{Un}$ segundo grupo se inclina por reconocerles valor vinculante a estos instrumentos merced a un reenvío a las figuras clásicas del derecho de contratos. Por ejemplo, Prado cree que las cartas fuertes importan obligaciones de hacer o incluso de pago directo al acreedor; ${ }^{22}$ Serrano califica al patrocinador que paga al acreedor como un deudor subsidiario que calza con el supuesto del artículo 1610 núm. $3^{\circ} \mathrm{CC} \cdot{ }^{23}$ Corral estima que, salvo ciertos modelos de cartas, ellas son obligatorias desde el punto de vista jurídico, carácter que se refuerza si pacta (incluso en una carta débil) una cláusula penal para garantizar el incumplimiento del compromiso asumido por el patrocinador, ${ }^{24}$ Baraona considera que, con independencia de que se trate de cartas débiles o fuertes, ellas pueden explicarse bajo la estructura general de la promesa (que define como un compromiso de comportamiento futuro), porque vienen a dar cuenta de una relación jurídicamente relevante donde el patrocinador de verdad no ha querido generar una obligación jurídicamente ejecutable, pero que sí tiene valor en términos jurídicos para legitimar la reclamación de una indemnización de perjuicios. ${ }^{25}$

\section{La calificación de la carta de 18 de octubre de 1996}

La sentencia de la Corte Suprema de 11 de enero de 2011 no se ocupa de determinar la naturaleza y alcance de las cartas de patrocinio en el derecho

\footnotetext{
${ }^{20}$ Prado, cit. (n. 5), p. 27.

${ }^{21}$ En este sentido, por ejemplo, Prado, cit. (n. 5), pp. 74-76; Chaparro, cit. (n. 7), p. 107; CAPrile, cit. (n. 1), p. 540, y los informes de los abogados Gabriel Cáceres Squella, Juan Agustín Figueroa Yávar y René Abeliuk Manasevich evacuados separadamente en el caso de la Universidad de la República referido, supra, II.

${ }^{22}$ Prado, cit. (n. 5), pp. 76-83.

${ }^{23}$ Serrano, cit. (n. 7), pp. 178-179.

${ }^{24}$ Corral TAlciani, Hernán, La 'cláusula penal'. Función y eficacia del contrato penal en el derecho chileno, Editorial Jurídica de Chile, Santiago, 2013, pp. 67-68.

${ }^{25}$ Baraona, cit. (n. 8), p. 376.
} 
chileno con carácter general, y sólo aborda la eficacia del documento datado el 18 de octubre de 1996 como fuente de obligaciones civiles. El problema aparece planteado de forma inversa, pues se procede sin consideración del carácter del instrumento donde se contienen las obligaciones cuya fuerza vinculante se discute como causa de pedir.

En Chile existe en torno a las cartas de patrocinio una falta de tipicidad socioeconómica lo suficientemente precisa y consolidada, lo que impide que el operador jurídico pueda contar con criterios de certeza a la hora de enfrentar el sinnúmero de problemas que conlleva su utilización en el tráfico, sobre todo cuando ellas se otorgan en el marco de un proceso de financiamiento que involucra grupos empresariales o factores de conexión. ${ }^{26}$ De lo que se ha dicho en el apartado precedente se sigue que esta falta de tipicidad, que suele ser una cuestión de común ocurrencia en el ámbito bancario (y que reconoce expresamente el considerando $11^{\circ}$ de la sentencia que motiva estos comentarios), ${ }^{27}$ dificulta su correcto encuadre dogmático, como fácilmente se aprecia en las distintas soluciones ofrecidas en el derecho comparado para explicar los efectos que se producen entre el acreedor y el patrocinador. ${ }^{28}$ Por eso, resulta acertada la descripción de las cartas de patrocinio como una figura de gran polisemia o plasticidad, ${ }^{29}$ que comporta el reemplazo de los instrumentos jurídicos tradicionales, como la fianza, el aval o la boleta

${ }^{26} \mathrm{El}$ fenómeno también se observa en el derecho comparado. Véase, por ejemplo, CaBriLlac, Michel; Mouly, Christian, Droit des sûretés, Litec, París, 1997, p. 394; Perchinunno, Maria Colomba, "Il danno dell'affidamento sucitato dalla lettera di patronage", Contratto e Impresa, 2006, n 3, p. 614; Valenzuela Garach, Fernando, "La 'seriedad' de las llamadas cartas de patrocinio", Revista de Derecho Mercantil, 1987, n 185-186, p. 366.

${ }^{27}$ SÁnchez-Calero Guilarte, Juan, "Valor jurídico de las cartas de garantía o cartas de patrocinio", en Sánchez Calero, Fernando; Sánchez-Calero G., Juan (editores), Comentarios a jurisprudencia de derecho bancario y cambiario, Centro de documentación y bursátil, Madrid, 1993, I, p. 545.

${ }^{28}$ Sobre ellas, entre otros, AlCalde, cit. (n. 8), pp. 114-152; De Castro Martín, José L., Las cartas de patrocinio, Cuadernos del Consejo General del Poder Judicial, Madrid, 1994, pp. 147-212; SuÁrEZ GonZÁLEz, Carlos, Las declaraciones de patrocinio. Estudio sobre las denominadas "cartas de confort», La Ley, Madrid, 1994, pp. 85-196. Por su parte, PRADO, cit. (n. 5) propone un acercamiento fragmentario a distintos encuadres posibles, como declaración unilateral de voluntad (pp. 28-30), estipulación a favor de otro (pp. 30-32), fianza (pp. 37-43), solidaridad (pp. 64-65), compromiso moral (pp. 73-76), obligación de hacer (pp. 76-79) u obligación de resultado (pp. 79-82).

${ }^{29}$ Véase, entre otros: Block, K.; Steiner, J., "Comfort letters. Casual drafting can turn one into a guarantee", New York Law Journal, 2004, Vol. 231, n 13, pp. 1-2; Cabrillac y Mouly, cit. (n. 26), p. 394; Domínguez Pérez, Eva M., "Problemática de las cartas de patrocinio. Comentarios a algunos recientes pronunciamientos jurisprudenciales", Revista Crítica de Derecho Inmobiliario 2006, nº 694, p. 785; Perchinunno, cit. (n. 26), p. 614; Sacasas, Rene; Wiesner, Don, "Comfort letters: the legal and business implications", Banking Law Journal, 1987, n 313, pp. 313-338, p. 315; VALENZUELA GARACH, cit. (n. 26), p. 368. 
bancaria de garantía, por otro destinado a operar una función de garantía bajo criterios económicos ${ }^{30} \mathrm{~A}$ fin de cuentas, ella se endereza a cumplir una función de garantía por la vía de ampliar la agresión de patrimonios respecto del acreedor. ${ }^{31}$ Ante este panorama, la respuesta más satisfactoria de las ofrecidas por la doctrina comparada es aquella que las considera como un negocio de garantía indemnizatoria. ${ }^{32}$ Pero, aun cuando sea así, la forma en que el riesgo que envuelven es asumido por el patrocinador sólo se podrá establecer una vez que se ha interpretado, integrado y calificado la carta, conectando su regla contractual con la responsabilidad que atañe a este último. ${ }^{33}$ Este es el núcleo del problema, pues las cartas de patrocinio plantearán siempre la necesidad de interpretación. La razón es doble: en primer término, dado que no existe generalmente un contenido predeterminado para estos documentos y ellos quedan entregados a la libre decisión del suscriptor; y en segundo lugar, porque en la redacción de una carta de patrocinio se emplean de forma consciente términos ambiguos o que buscan diluir el compromiso. ${ }^{34}$

Con todo, al exponer su eficacia vinculante, la doctrina comparada está conteste en distinguir dos clases de cartas de patrocinio, llamadas, respectivamente, cartas vinculantes o "fuertes" y cartas no vinculantes o "débiles", cada una con una distinta disciplina y grado de vinculación para quien las suscribe. ${ }^{35}$ De esta clasificación también se hace cargo la demanda del banco BICE y la contestación de las sociedades patrocinadoras: la primera para afirmar la obligatoriedad del compromiso manifestado en la carta de 18 de octubre de 1996, y las segundas para situar esa declaración en el ámbito de la mera cortesía. Pero a esta distinción no importa negar correlativamente la eficacia jurídica

\footnotetext{
${ }^{30}$ Véase, entre otros, Álvarez, cit. (n. 11), pp. 1456-1457; Arcos VieIra, Ma. Luisa, "Sentencia de 13 de febrero de 2007: Reclamación de la entidad bancaria prestamista frente al emitente de una carta de patrocinio, tras el incumplimiento del contrato por la empresa prestataria. Cartas de patrocinio: doctrina. Requisitos para la consideración de las cartas de patrocinio como contrato de garantía. Carta de patrocinio y mandato de crédito", Cuadernos Civitas de Jurisprudencia Civil 2008, n 77, p. 522; AvilÉs García, Javier, "Evolución de las garantías personales en el Derecho español", Anuario de Derecho Civil 1996, XLIX, nº 3, p. 1079; BRUno, Giovanni, Le lettere di patronage nel rapporti economici, Liguori, Nápoles, 2004, p. 203; SACASAS y Wiesner, cit. (n. 29), p. 338; Sánchez-Calero G., cit. (n. 27), p. 547.

${ }^{31}$ Aedo Barrena, Cristián, "Las garantías del acreedor frente al incumplimiento. Especial referencia a la boleta bancaria de garantía", Revista Chilena de Derecho, 2008, Vol. 35, n 2, pp. 296-298.

${ }^{32}$ Véase, por todos, Netter, Emmanuel, Les garanties indemnitaires, Presses Universitaires d'AixMarseille, Aix-Marseille, 2014.

${ }^{33}$ Véase, respectivamente, AlCALDE, cit. (n. 8), pp. 57-106 y 169-183.

${ }^{34}$ Arcos, cit. (n. 30), p. 525.

${ }^{35}$ Para el caso chileno, la denominación figura ya en Prado, cit. (n. 5), p. 16.
} 
de esta clase de instrumentos. ${ }^{36}$ Una carta débil no es la que no tiene efectos jurídicos cualesquiera, sino aquella cuyos eventuales efectos obligacionales no nacen de la declaración de voluntad sino de las reglas de la responsabilidad in contrahendo por la confianza suscitada por la declaración. De igual manera, una carta fuerte es aquella que contiene un deber de prestación que nace de una promesa de futuro, aunque ella no puede caracterizarse como una fianza.

Las cartas débiles presentan un contenido bastante flexible donde comparecen declaraciones sobre ciertos hechos relevantes destinadas a comunicar al acreedor que el patrocinador conoce la existencia del crédito que se concede al patrocinado y que, de forma explícita o implícita, manifiesta su conformidad con tal operación. ${ }^{37}$ Además, y para zanjar toda duda al respecto, esta modalidad de cartas suele llevar aneja una cláusula de no obligatoriedad a favor del patrocinador, para hacer explícito el propósito de que éste no se convierte en garante de la obligación contraída por el deudor patrocinado. De ahí que, en principio, estas cartas sólo engendran un compromiso moral para el otorgante, que (se cree) es irrelevante ante el derecho, sin perjuicio de las consecuencias jurídicas que el incumplimiento de un compromiso de esta clase puede eventualmente generar. ${ }^{38}$ Muchas veces el destinatario conoce la información que el patrocinador declara en la carta. Siendo así, el hecho de que se efectúe una declaración tan inútil a efectos de transmitir información sólo adquiere racionalidad si, adicionalmente a esa información que se suministra, el dato declarado tiene un valor adicional para el acreedor. ${ }^{39}$

Desde el punto de vista retórico, hay un factor adicional que tiende a diluir la fuerza obligatoria de una carta de patrocinio y que viene dado por la propia forma de utilización del español en el país. Entre otros rasgos, ésta se caracteriza por la atenuación, vale decir, por expresar algo de manera menos intensa que aquella que verdaderamente corresponde al pensamiento del emisor. ${ }^{40}$ Se utilizan

\footnotetext{
${ }^{36}$ Las ideas que siguen están tomadas de CARrasco, cit. (n. 12), p. 903.

37 Sánchez-Calero Guilarte, Juan, El contrato autónomo de garantía. Las garantías a primera demanda, Centro de documentación bancaria y bursátil, Madrid, 1995, p. 120.

${ }^{38}$ Como explica GiLIKER, Paula, "Taking comfort in certainty: to enforce or not to enforce the letter of comfort", Lloyd's Maritime and Commercial Law Quarterly 2004, n² 2, p. 224, en el derecho continental el título de esta responsabilidad se busca en las reglas de la responsabilidad extracontractual, mientras que el Common Law se intenta construir a partir de la figura de la misrepresentation (declaración que no está de acuerdo con la realidad y que es hecha con la intención de engañar), que puede asimilarse al dolo.

${ }^{39}$ Carrasco, cit. (n. 12), p. 907.

${ }^{40}$ V. Puga, Juana, Cómo hablamos cuando hablamos. La atenuación en el castellano de Chile, Ceibo, Santiago, 2014.
} 
así construcciones semánticas que quieren restar intensidad a la declaración, de suerte que el tenor de ella aparece formulado a través de un registro mucho más suave que el sentido que quiere transmitir. Es verdad que entre las reglas sobre interpretación de los contratos no existe un equivalente al artículo $20 \mathrm{CC}$, según el cual las palabras de una ley deben entenderse según su sentido natural y obvio, conforme al uso general de las mismas. Pero eso no puede impedir que las palabras de una declaración de voluntad se entiendan a partir de su sentido y no de su tenor literal, pues la intención de las partes se manifiesta claramente mediante el modo de hablar que constituye su marco de referencia cultural (artículo $1560 \mathrm{CC}) .{ }^{41}$ Ante la duda, siempre se debe preferir el sentido de una declaración que produzca algún efecto obligacional frente a aquel que no tenga consecuencia alguna (artículo $1562 \mathrm{CC}$ ), ${ }^{42}$ sobre todo cuando se trata de una declaración formulada entre partes sofisticadas. ${ }^{43}$ Asimismo, algunos elementos adicionales comparecen para precisar el sentido de las declaraciones de una carta de patrocinio. Así ocurre, por ejemplo, con la existencia de declaraciones usuales existentes en formularios (artículo 1563 II CC) o la ejecución que de ellas haya hecho el deudor con aprobación del acreedor (artículo 1564 III CC). La costumbre bancaria constituye aquí un poderoso elemento hermenéutico (artículo $6^{\circ}$ C.Com), pues la función de garantía que comporta la carta acaba permeando la totalidad del documento por difusa que ella sea en razón de las expectativas que crea en el acreedor (artículo 1564 I CC). ${ }^{44}$ Por último, la ambigüedad en la redacción de alguna de las declaraciones de la carta cederá siempre contra el patrocinador (artículo 1566 II CC). ${ }^{45}$

Por su parte, las cartas fuertes incluyen declaraciones de mantenimiento, que están dirigidas a asegurar al acreedor la permanencia de ciertas circunstancias que fueron consideradas relevantes al momento de conceder el crédito, y declaraciones de compromiso, las cuales comportan deberes de prestación propios que asume el patrocinador, los que generalmente consisten en obligaciones de hacer (por ejemplo, conservar un determinado porcentaje

\footnotetext{
${ }^{41}$ Alcalde SiLVA, Jaime, "Una nueva lectura de las normas de interpretación de los contratos", en: Corral Talciani, H.; Rodríguez Pinto, M. S. (editores), Estudios de Derecho civil II, LexisNexis, Santiago, 2007, p. 128.

${ }^{42}$ Arcos, cit. (n. 30), p. 528.

${ }^{43}$ Véase, en general, Montero Iglesis, Marcelo, "Notas sobre el impacto de la formación del consentimiento en la interpretación del contrato entre partes sofisticadas", en De la Maza G., Iñigo (Editor), Cuadernos de análisis jurídico. Colección derecho privado, III: Temas de contratos, Ediciones Universidad Diego Portales, Santiago, 2011, pp. 115-129.

${ }^{44}$ Carrasco, cit. (n. 12), pp. 907-908.

${ }^{45}$ Arcos, cit. (n. 30), p. 535.
} 
de participación en la sociedad deudora), aunque sin descartar obligaciones de asistencia financiera. ${ }^{46}$ Comportan, entonces, una forma de garantía personal atípica, con todas las consecuencias que ello implica. ${ }^{47}$

En la situación resuelta por la sentencia de la Corte Suprema de 11 de enero de 2011, la cuestión estribaba en determinar si la carta que las sociedades demandadas suscribieron a favor del Banco BICE con fecha 18 de octubre de 1996 comportaba una carta fuerte que engendraba obligaciones y responsabilidades o, por el contrario, sólo tenía un carácter débil y entrañaba una vinculación que no trascendía en principio el ámbito de la moral comercial. Cabe recordar que, al menos desde el punto de vista doctrinal y forense, éste es el carácter que preferentemente se atribuye a las cartas de patrocinio en el país, sin que importe demasiado su particular redacción. ${ }^{48}$

El análisis de la fuerza vinculante de una carta de patrocinio comprende un proceso equivalente al de cualquier declaración de voluntad, de suerte que se debe partir de su texto y de la intención que a través de él manifiesta el otorgante (artículo 1560 CC). ${ }^{49}$ Cumple así emprender el proceso de construcción de la regla prestacional que se contenía en la carta que ahora interesa y discernir cuál era el grado de obligatoriedad que ella comportaba. ${ }^{50}$ Pues bien, tras individualizar a las sociedades que concurrían a su suscripción y que fueron demandadas posteriormente por el banco destinatario, el instrumento de 18 de octubre de 1996 señalaba en este sentido: ${ }^{51}$

"Los comparecientes por sí y en representación de Inversiones Villarrica Limitada, se comprometen para con el Banco BICE, mientras exista alguna deuda directa o indirecta pendiente de la sociedad Inversiones Villarrica Limitada, para con el mismo Banco a lo siguiente:

${ }^{46}$ De ahí que, por ejemplo, el artículo 2322 del Code Civil francés defina la carta de patrocinio (lettre d'intention) como «l'engagement de faire ou de ne pas faire ayant pour objet le soutien apporté à un débiteur dans l'exécution de son obligation envers son créancier».

${ }^{47}$ La garantía consiste aquí en una obligación condicional que tiene por contenido fundamental el asegurar la verdad de una situación presente o la realización de un evento futuro. Este concepto es similar al propuesto por TAPIA RodRíGUEZ, Mauricio, "Noción de garantía", en: Tapia Rodríguez, M.; Gaitán Martínez, José A.; Juricic Cerda, Daniel; Salah Abusleme, María A.; Mantilla Espinosa, Fabricio (directores), Estudios sobre garantías reales y personales. Libro homenaje al Profesor Manuel Somarriva Undurraga, Editorial Jurídica de Chile, Santiago, 2009, I, p. 28.

${ }^{48}$ Véase supra, III, 1.

${ }^{49}$ Sobre este proceso: AlCALDE, cit. (n. 8), pp. 65-74.

${ }^{50}$ Vidal Olivares, Álvaro, "La construcción de la regla contractual en el derecho civil de los contratos", Revista de Derecho de la Pontificia Universidad Católica de Valparaíso 2000, Vol. XXI, pp. 209-227.

${ }^{51} \mathrm{Su}$ texto viene reproducido en el considerando $5^{\circ}$ de la Sentencia de Corte Suprema, 11 de enero de 2011. 
$1^{\circ}$. Los comparecientes por sí o a través de sociedades en las que son los únicos socios mantendrán sus derechos en Inversiones Villarrica Limitada, derechos que a esta fecha ascienden al $100 \%$ de la participación en la misma, como asimismo también mantendrán sus participaciones en las sociedades socias de ésta [sic] última.

$2^{\circ}$. Inversiones Villarrica Limitada, en ningún momento contraerá endeudamientos superiores a 0,6 veces su patrimonio, entendiendo por endeudamiento como la totalidad de sus pasivos exigibles dividido por la totalidad del patrimonio. Dicho endeudamiento podrá llegar a 0,8 si se trata de créditos otorgados y aprobados por el Banco BICE.

$3^{\circ}$. Entregar información financiera relativa a las sociedades Inversiones Villarrica Limitada e Inmobiliaria Ginebra S.A. y Comercial Berna S.A., especialmente en lo referente a sus balances auditados y estados de resultado al 30 de junio y al 31 de diciembre de cada año, con un desfase no superior a 60 días.

$4^{\circ}$. Inversiones Villarrica Limitada no podrá ceder o enajenar activos fijos o financieros que representen más de los $50 \%$ de los mismos, entendidos estos últimos como las inversiones o participaciones en otras sociedades, sin aviso previo al Banco BICE.

$5^{\circ}$. Inversiones Villarrica Limitada no se constituirá en avalista sin previo aviso al Banco BICE.

$6^{\circ}$. Inversiones Villarrica Limitada no constituirá garantías a favor de terceros sin previo aviso al Banco BICE.

$7^{\circ}$. Inversiones Villarrica Limitada no otorgará créditos a sus socios o empresas relacionadas que en su totalidad excedan a $\$ 100.000 .000$, salvo previo aviso al Banco BICE y siempre que se cumplan con las demás restricciones establecidas en este documento.

$8^{\circ}$. El o los avisos a que se refiere en los números $4^{\circ}, 5^{\circ}, 6^{\circ}$ y $7^{\circ}$ de este documento, deberá(n) ser enviado(s) al Banco BICE con una anticipación previa de 60 días corridos, a contar de la fecha en que acontezcan el o los hecho(s) en cuestión. A su vez el Banco BICE se podrá oponer a la realización de la operación informada por Inversiones Villarrica y, en el evento que éste [sic] último persista en su ejecución, se deberán prepagar totalmente las deudas que se encontraran vigentes o pendientes.

$9^{\circ}$. En el caso de no cumplimiento de las obligaciones y compromisos establecidos en esta carta, los comparecientes por sí y en representación de Villarrica Limitada deberán cancelar [=pagar] todas las deudas directas e indirectas que dicha sociedad mantenga con el Banco BICE. 
El texto de la carta evidenciaba, por consiguiente, que ella se encontraba relacionada con una operación de crédito destinada a conceder una línea de financiamiento a la sociedad antes individualizada o su aval, lo que descarta que su contenido constituyese una mera declaración unilateral de voluntad o de simple cortesía. ${ }^{52}$ Por eso, resuelve correctamente la Corte Suprema cuando estima que los jueces de la instancia han equivocado los fundamentos de su decisión (considerando $4^{\circ}$ ). Sin duda, la carta en cuestión era de carácter fuerte y comportaba distintos deberes de prestación respecto de las sociedades suscriptoras. A partir de esta premisa, el razonamiento de la Corte se estructura sobre los principios generales de la contratación y las fuentes de las obligaciones (considerandos $6^{\circ}$ y $7^{\circ}$ ), desde los que extrae su conclusión acerca de la fuerza vinculante de la declaración unilateral de voluntad (considerando $9^{\circ}$ ). Esto le permite afirmar en el considerando $8^{\circ}$ :

"Que sobre la naturaleza de la carta en cuestión, el banco demandante ha sostenido en su recurso, con la finalidad de dotarla de obligatoriedad, que constituye la aceptación de las sociedades demandadas de la oferta formulada por su parte, dando origen a un contrato, postulado que no pasa de ser una afirmación sin fundamento fáctico, conforme a los razonamientos contenidos en la sentencia del tribunal a quo, reproducidos por el fallo impugnado".

Para la Corte Suprema, la declaración unilateral de voluntad constituye una fuente de obligaciones y, por consiguiente, la alegación del banco que ha fundado el recurso de casación en el fondo carece de cualquier justificación en sentido de privar a la carta de fuerza vinculante. ${ }^{53}$ Esta calificación no es novedosa y concuerda con alguna jurisprudencia anterior. ${ }^{54}$ Donde sí hay interés es en la obligatoriedad que se le asigna a la carta de patrocinio suscrita por las sociedades demandadas, aunque soslayando el problema de su calificación. Señala al respecto el considerando $10^{\circ}$ :

[...] el contenido de la carta en análisis se encuadra, en un sentido

\footnotetext{
${ }^{52}$ En el mismo sentido, ya Prado, cit. (n. 5), pp. 29-30.

${ }^{53}$ PeÑallillo, cit. (n. 4), p. 134 señala que las dos características esenciales de la declaración unilateral de voluntad son (i) su irrevocabilidad y (ii) su retroactividad. La primera significa que, una vez efectuada, el declarante no puede arrepentirse de la deuda que ha asumido. La segunda denota el hecho de que la aceptación dada por quien acaba siendo acreedor se retrotrae al tiempo en que la voluntad se emitió. ${ }^{54}$ Véase, por ejemplo, las referencias que da Barrientos Grandón, Javier, El Código Civil. Su jurisprudencia e historia. Edición crítica, concordada, comentada y anotada, Thomson Reuters, Santiago, 2016, T. II, pp. 314-316.
} 
amplio, dentro del concepto de hecho voluntario a que se refiere el artículo 1437 del Código de Bello y que reúne los requisitos del artículo 1445 del cuerpo normativo citado. [...] Se trata de una obligación determinada, asumida por los suscribientes a raíz del incumplimiento de ciertas conductas u obligaciones que se detallan, manifestada con un objetivo específico y concreto, el pago bajo ciertas condiciones de la deuda de un tercero, que conforme al instrumento, si bien se refiere una persona jurídica diversa y que no comparece al acto, se encuentra vinculada con cada una de las demandadas por lazos societarios que las llevó a adquirir las obligaciones de que se trata. No puede en ningún caso sostenerse al tenor de la redacción de la carta mencionada, que se trata de una declaración simplemente moral o de buena voluntad, que no impone obligación alguna para sus suscribientes. [...] del tenor de las defensas de las demandadas que comparecieron al juicio sólo se concluye el cuestionamiento a la obligatoriedad de las declaraciones por ellas mismas manifestadas, al insistir que no constituye una fuente de obligaciones de aquellas que expresamente estatuye el legislador, argumentación que de acuerdo a lo dicho debe desestimarse.

Pero la Corte Suprema va más allá todavía y, después de haber afirmado el carácter vinculante de la carta de 18 de octubre de 1996, intenta esbozar una cierta calificación para ella en el considerando $11^{\circ}$ :

[...] no puede dejar de advertirse en la actualidad la existencia de un sinnúmero de operaciones mercantiles que escapan a la teoría clásica de los contratos, que pretenden afianzar o reforzar comercialmente una operación, con la finalidad, entre tantas, de contribuir al mejor posicionamiento de una parte ante la otra, y que [,] de acuerdo a su destino, podrán contener estipulaciones con carácter vinculante, dependiendo de la existencia de obligaciones entre sus cláusulas, en cuyo caso, se apartan de las cartas de intención propiamente dichas o de declaración de buena voluntad y constituyen ya sea declaraciones unilaterales de voluntad, precontratos o bien contratos definitivos, debiendo ceñirse las obligaciones, en el primer caso, a las disposiciones de quienes las hayan otorgado, con respeto al orden público y a derechos de terceros, según las reglas generales aplicables a los contratos.

Con todo, el resultado de este encuadre aproximativo es confuso y ambiguo. Confuso, porque equipara las cartas de patrocinio con las figuras de las cartas de intenciones, de las cuales se diferencia por su grado de 
obligatoriedad. ${ }^{55}$ Ambiguo, porque no indica cuál es la real eficacia de una carta de patrocinio, sino sólo la fuente desde la cual emana esa obligatoriedad y por su función en el itinerario contractual. ${ }^{56}$ No es indiferente que ellas comporten una declaración unilateral de voluntad, un contrato preparatorio (o precontrato según la terminología de la sentencia) o un contrato definitivo, por las consecuencias que se siguen para determinar cuál es la específica obligación asumida por el patrocinador y también por los requisitos que se exigen para que cada una de esas figuras exista. Pero además con esta afirmación la Corte Suprema parece asumir una rígida distinción entre las aquí llamadas cartas fuertes y débiles, pues sólo las primeras darán origen a un vínculo jurídicamente exigible entre el acreedor y el patrocinador, siendo las segundas una mera expresión de un acuerdo de intenciones o de manifestaciones de buena voluntad. De esta forma queda fuera la que es quizá el aspecto más interesante de estos instrumentos, como es la manera de construir la responsabilidad del patrocinador. Si bien en las cartas "débiles" existe cierto consenso en cuanto a que deben ser consideradas como meros acuerdos morales, sujetos a la confianza que existe entre las partes, la eventual responsabilidad del patrocinador deriva precisamente de la frustración de esa confianza. ${ }^{57}$ Respecto de las cartas "fuertes", se han intentado los más variados encuadres dogmáticos para circunscribirlas dentro de categorías ya existentes. ${ }^{58}$ Pese a estos esfuerzos, ninguna de esas soluciones es aceptable,

${ }^{55}$ Las cartas de intenciones (letters of intent) son documentos unilaterales merced a los cuales una o ambas partes de una negociación (i) declaran su deseo de comenzar o continuar dicha negociación para llegar a un acuerdo definitivo; (ii) fijan los eventuales pactos alcanzados hasta ese momento y estipulan que la negociación futura debe comenzar desde ellos; (iii) enumeran los puntos sobre los cuales se debe alcanzar un acuerdo satisfactorio y, si cabe, adelantan una cifra para el precio del contrato; y (iv) establecen reglas obligatorias con carácter temporal con el propósito de ordenar el posterior proceso de negociación. Cfr. CARRASCO, cit. (n. 12), p. 69.

${ }^{56}$ La propia remisión a otra categoría, ya de por sí ambigua en cuanto a su obligatoriedad como son las cartas de intenciones, hace que no se adopte una decisión sobre el efectivo vínculo que surge para el acreedor y el patrocinador mediante el otorgamiento de una carta de patrocinio. De hecho, Arcos, cit. (n. 30), p. 532 observa la misma dificultad respecto de la calificación de una carta de patrocinio como mandato de crédito, pues esta figura carece igualmente de una tipicidad clara en la mayoría de los sistemas jurídicos. Sobre los problemas de vinculación derivados de las cartas de intenciones, véase Carrasco, cit. (n. 12), pp. 72-89.

${ }^{57}$ AlCALde, cit. (n. 8), pp. 173-177.

${ }^{58}$ Entre las distintas explicaciones ofrecidas sobre la naturaleza jurídica de las cartas de patrocinio comparecen las teorías de la oferta contractual, la escrituración de compromisos previos, el contrato marco, la fianza, el contrato de garantía, el mandato de crédito, las relaciones de colaboración empresarial, la carta de recomendación, la firma de favor, la garantía a primer requerimiento, la promesa de hecho ajeno, la estipulación a favor de otro, la expromisión, la obligación de hacer, la cláusula penal, y la caución juratoria. Véase el análisis de ellas en AlCALDE, cit. (n. 8), pp. 114-152 con referencia al derecho chileno. 
porque elimina la especificidad que las cartas de patrocinio poseen dentro del elenco de las garantías, y sustraen la funcionalidad que ellas comportan y que las hace apetecibles en sí como forma de resguardo para el acreedor, a pesar de su conocida ambigüedad. ${ }^{59}$

Por estas razones, y sin importar si se trata de cartas "fuertes" o "débiles", las cartas de patrocinio suponen el equivalente funcional de un negocio jurídico de garantía, por el cual una persona (el patrocinador), para estimular una iniciativa de otra (el acreedor), asume todo o parte del riesgo de confianza relacionado con ella, siempre dentro de los contornos de un instrumento variable por naturaleza en sus distintos contenidos posibles. ${ }^{60} \mathrm{Tal}$ riesgo se asegura mediante una promesa vinculante de comportamiento correcto $\mathrm{y}$ transparente que asume el patrocinador hacia el acreedor y que puede traducirse en los más diversos deberes de información o prestación cuya infracción obliga a indemnizar el daño causado. ${ }^{61}$ De este modo, en última instancia, el punto de convergencia entre ambas clases de cartas se sitúa en la finalidad esencialmente indemnizatoria que ellas poseen, siendo el título de dicha responsabilidad el que dependerá de la clase de carta de que se trate. ${ }^{62}$ Por cierto, esta función es importante cuando se produce el incumplimiento de la obligación garantizada, pero no constituyen la principal característica de las cartas de patrocinio. Ellas, por su carácter de garantía indemnizatoria, no se enderezan propiamente hacia una proyectada indemnidad del acreedor, sino que cumplen una labor de prevención de los riesgos involucrados en el financiamiento. ${ }^{63}$

Concebir las cartas de patrocinio como una garantía indemnizatoria tiene consecuencias prácticas importantes. Una de ellas es su posible utilización para salvar la restricción que establece el artículo 117 núm. 1 de la Ley 20.720, de reorganización y liquidación de activos de empresas y personas (LRLAEP) respecto de las obligaciones vencidas que autorizan a solicitar la apertura de un proceso concursal de liquidación. La primera parte de este supuesto de hecho reitera el que ya existía en el artículo 43 de la Ley 18.175, con

\footnotetext{
${ }^{59}$ Álvarez, cit. (n. 11), p. 1455.

${ }^{60}$ Con algunos matices, esta formulación se corresponde con la definición clásica de contrato de garantía que ofrecen EnNecCerus, Ludwig, Derecho de las obligaciones (trad. de B. Pérez González y J. Alguer), Bosch, Buenos Aires, 1948, T. II, p. 493; Messineo, Francesco, Doctrina general del contrato (trad. R. O. Fontanarrosa, S. Sentis Melendo y M. Volterra), Ediciones Jurídicas Europa-América, Buenos Aires, 1986, T. I, p. 386; y Puig Brutau, José, Fundamentos de derecho civil, II-2, Bosch, Barcelona, 1956, p. 529.

${ }^{61}$ Bruno, cit. (n. 30), pp. 3 y 203.

${ }^{62}$ Alcalde, cit. (n. 8), pp. 206-207.

${ }^{63}$ Mazeaud, Vincent, L'obligation de couverture, IRJS, París, 2010, p. 385.
} 
algunas variaciones menores, pues permite que se inicie un procedimiento concursal de liquidación cuando la empresa deudora ha cesado en el pago de una obligación que conste en título ejecutivo con el acreedor solicitante. ${ }^{64}$ La novedad es que el supuesto se complementa ahora con una limitación que favorece a los deudores: dicho incumplimiento no podrá invocarse para solicitar el inicio de tal procedimiento concursal respecto de los fiadores, codeudores solidarios o subsidiarios, o avalistas de la empresa deudora que ha cesado en el pago de las obligaciones garantizadas por éstos. Este obstáculo no existe en las garantías indemnizatorias, donde el garante se compromete directamente hacia el acreedor.

En la carta de patrocinio que servía de causa de pedir en el caso que motiva estos comentarios, los compromisos asumidos eran principalmente de hacer (núm. $3^{\circ}$ ), de no hacer (núm. $1^{\circ}, 2^{\circ}$ y $4^{\circ}$ al $8^{\circ}$ ) y de dar (núm. $8^{\circ}$ y 9), pero la prestación no siempre recaía sobre las sociedades suscriptoras. Varias de las obligaciones suponían el hecho de la sociedad patrocinada que no comparecía en la carta, de suerte que comportaban una promesa de hecho ajeno (núm. $2^{\circ}$ y $4^{\circ}$ al $7^{\circ}$ ). Parte del núm. $8^{\circ}$ era, además, una obligación instrumental, pues señalaba la oportunidad en que debía entregarse la información que había de proporcionar la sociedad patrocinada. El resto de ese núm. $8^{\circ}$ era una suerte de cláusula penal establecida para el incumplimiento de las obligaciones de no hacer que pesaban sobre la sociedad patrocinada, la que avaluaba los perjuicios derivados del incumplimiento por parte de un tercero y no del prometiente (artículo $1450 \mathrm{CC}$ ). En fin, el núm. $9^{\circ}$ se asemejaba a una cláusula penal, dado que la exigibilidad de esa obligación dependía del incumplimiento de los compromisos anteriores (no todos ellos de cargo de las sociedades patrocinadoras), pero con la particularidad de que la obligación de pago de las sociedades suscriptoras respecto de las deudas de la patrocinada venía configurada como un supuesto a la vez de deuda directa y de diputación al pago ("los comparecientes por sí y en representación de Villarrica Limitada, deberán cancelar $[=$ pagar $]$ todas las deudas directas e indirectas que dicha sociedad mantenga con el Banco Bice"). Propiamente, entonces, la carta no suponía una estructura obligacional semejante a la fianza, porque no se garantizó que el cumplimiento de la obligación del tercero se produciría de cualquier

\footnotetext{
${ }^{64} \mathrm{El}$ artículo 43 núm. 1 de la Ley 18.175 (después incorporado por la Ley 20.080 con la misma numeración en el Libro IV del Código de Comercio) exigía que el deudor ejerciese una actividad comercial, industrial, minera o agrícola y que la cesación de pagos afectase a una obligación de carácter mercantil.
} 
forma (artículos $2335 \mathrm{CC}$ ). ${ }^{65}$ En realidad, los patrocinadores se obligaban al pago de las deudas directas e indirectas de la sociedad patrocinada en caso de un incumplimiento de las obligaciones que por la propia carta se prometían respecto de esa sociedad y de aquellos compromisos que incumbían a ellas, como era el directo de no disminuir su participación accionaria en Inversiones Villarrica Limitada y las promesas de hecho ajeno del resto de la carta ${ }^{66}$

Dada esta estructura, la decisión de la Corte Suprema fue correcta. El argumento principal de la Sentencia de la Corte Suprema de 11 de enero de 2011 era que cabía rechazar el recurso de casación deducido por el banco, confirmando así el rechazo de la demanda de cobro de pesos, en razón de la ausencia de los presupuestos concretos de la pretensión ejercida. Ella era una acción indemnizatoria contractual, donde el monto de los perjuicios se fijaba en el montante de las deudas directas e indirectas que la sociedad patrocinada tenía con el banco demandante (núm. $9^{\circ}$ de la carta de 18 de agosto de 1996). Sin embargo, las obligaciones de informar que se indicaban habían sido incumplidas por Inversiones Villarrica Limitada no estaban vinculadas con las sociedades patrocinadoras más que a través de la figura de una promesa de hecho ajeno. De ahí esas sociedades sólo quedaban obligadas en rigor a la indemnización de los daños que se siguiesen para el banco del incumplimiento de la obligación prometida respecto del tercero (artículo $1450 \mathrm{CC}$ ). De considerarse que el núm. $9^{\circ}$ de la carta era una cláusula penal, ella aseguraba una obligación de valor indeterminado dado que con ella se avaluaban los perjuicios derivados de la negativa de la sociedad patrocinada de cumplir con aquella obligación de informar prometida por las sociedades suscriptoras. No existía, por tanto, una contraprestación equivalente que sirviese de referencia. Esto significaba que quedaba a la prudencia del juez moderar la pena, cuando atendidas las circunstancias pareciese enorme (artículo 1544 IV CC), y que el banco demandante debía probar la cuantía y procedencia de los daños que demandada. En otras palabras, la cuantía de las obligaciones de la sociedad deudora para con el banco no era de por sí extrapolable a la obligación indemnizatoria que correspondía a las sociedades patrocinadores, porque el acreedor había de demostrar que había

\footnotetext{
${ }^{65}$ Carrasco, cit. (n. 12), p. 910.

${ }^{66}$ Álvarez, cit. (n. 11), p. 1467, sostiene que, si el patrocinador pierde efectivamente el control sobre la sociedad deudora, queda obligado de manera más intensa que si sigue detentando el control originario sobre ella. En el caso que se comenta, eso no ocurrió porque fue la sociedad patrocinada la que enajenó sus activos y no las patrocinadoras. Se trató, en suma, del incumplimiento de la obligación descrita en el núm. $4^{\circ}$ de la carta y no en el núm. $1^{\circ}$.
} 
sufrido daños y que ellos estaban conectados con el ámbito de protección de la carta de patrocinio. Más todavía, cuando parte de la deuda que la sociedad patrocinada tenía con el banco estaba siendo discutida en otro tribunal. Ninguno de esos puntos fue acreditado por el banco, y la discusión quedó centrada en la calificación jurídica de la carta. La Corte acabó concluyendo que la carta era vinculante, porque engendraba un compromiso vinculante, pero que ese hecho no influía en lo dispositivo del fallo por no existir prueba suficiente que demostraba el perjuicio que el banco reclamaba.

\section{CONCLUSIONES}

Las consideraciones precedentes demuestran la importancia de la sentencia que se ha comentado. En ella la Corte Suprema se pronuncia por primera vez sobre la eficacia de una carta de patrocinio dada como garantía de una operación de financiamiento de un grupo empresarial, y lo hace atribuyéndole un innecesario carácter contractual. Sin embargo, y al igual que ha ocurrido en el derecho comparado, las razones esgrimidas por ella no permiten construir una doctrina jurisprudencial respecto de las cartas de patrocinio, porque el problema de su eficacia se aborda en relación con las fuentes de las obligaciones y no con el contenido de la garantía específica que significa para el acreedor el otorgamiento de una carta de patrocinio. En este sentido, el carácter inicial que el patrocinador y el acreedor asignen a la carta, incluso sustrayendo su obligatoriedad jurídica, no tiene efectos si existe un hecho generador de responsabilidad civil conforme a las reglas generales, el que puede estar tanto en la frustración de una confianza creada como en la infracción de concretos deberes de prestación. Por eso, y sin importar su carácter, las cartas de patrocinio comportan siempre una garantía indemnizatoria, donde la responsabilidad de patrocinador es propia y la discusión reside en configurar el factor de imputación subjetiva de ese deber respecto del patrocinador.

En el caso en cuestión, empero, el problema no estaba dado por la calificación de una carta de patrocinio como una declaración vinculante. Tal carácter fue reconocido por la Corte Suprema, aunque sin delimitar propiamente los contornos obligatorios de dicho instrumento. El problema fue de otra índole, pues el banco acreedor no logró demostrar los perjuicios que demandaba. En otros términos, su pretensión era clara en cuanto a la causa de pedir y fallaba en cuanto a la cosa pedida. El fundamento inmediato de su pretensión era la suscripción de una carta por parte de las sociedades demandadas donde se asumían una serie de compromisos fuertes. Pero se reclamaba como perjuicio 
el total de las deudas que la sociedad patrocinada tenía con el banco, sin que se hubiese demostrado ni la cuantía real de éstas (en parte discutidas en otro juicio) ni la conexión causal del incumplimiento de esas obligaciones con la promesa de hecho ajeno que era exigible respecto de las sociedades patrocinadoras.

\section{BIBLIOGRAFÍA}

Aedo Barrena, Cristián, "Las garantías del acreedor frente al incumplimiento. Especial referencia a la boleta bancaria de garantía", Revista Chilena de Derecho 2008, Vol. 35, nº 2, pp. 293-310.

Alcalde Silva, Jaime, "Una nueva lectura de las normas de interpretación de los contratos", en: Corral Talciani, H.; Rodríguez Pinto, M. S. (editores), Estudios de Derecho civil II, LexisNexis, Santiago, 2007, pp. 549-570.

Alcalde Silva, Jaime, "Las cartas de patrocinio: situación en Chile y en el derecho comparado", en: Tapia Rodríguez, M.; Gaitán Martínez, José A.; Juricic Cerda, Daniel; Salah Abusleme, María A.; Mantilla Espinosa, Fabricio (directores), Estudios sobre garantías reales y personales. Libro homenaje al Profesor Manuel Somarriva Undurraga, Editorial Jurídica de Chile, Santiago, 2009, T. I, pp. 237-277.

Alcalde Silva, Jaime, Las cartas de patrocinio. Criterios dogmáticos para su aplicación en Chile, Abeledo Perrot - Legal Publishing, Santiago, 2010.

Álvarez Lata, Natalia, "Sentencia de 18 de marzo de 2009: Carta de patrocinio fuerte. Asunción de compromisos claros e inequívocos por la patrocinante en caso de impago de la prestataria", Cuadernos Civitas de Jurisprudencia Civil 2009, nº 81, pp. 1447-1468.

Arcos Vieira, Ma. Luisa, "Sentencia de 13 de febrero de 2007: Reclamación de la entidad bancaria prestamista frente al emitente de una carta de patrocinio, tras el incumplimiento del contrato por la empresa prestataria. Cartas de patrocinio: doctrina. Requisitos para la consideración de las cartas de patrocinio como contrato de garantía. Carta de patrocinio y mandato de crédito", Cuadernos Civitas de Jurisprudencia Civil 2008, nº 77, pp. 511-536.

Aтti, A., "Nouve modelli di lettere di patronage", Contratto e impresa 1985, nº 3, pp. 973-976.

AvilÉs GarcíA, Javier, "Evolución de las garantías personales en el Derecho español", Anuario de Derecho Civil 1996, XLIX, nº 3, pp. 1073-1132.

Banco Santander (editores), Manual de riesgos (Capítulo 3: Manejo y control de garantías, Tema: Alcance de riesgos sobre distintos tipos de 
garantías), edición interna, Santiago, 2002.

Baraona González, Jorge, "La promesa en el Código Civill, en Elorriaga De Bonis, F. (coord.), Estudios de Derecho civil VII, Thomson Reuters, Santiago, 2012, pp. 360-376.

Barrientos Grandon, Javier, El Código Civil. Su jurisprudencia e historia. Edición crítica, concordada, comentada y anotada, Thomson Reuters, Santiago, 2016, T. II.

Bellis, Marc; Coipel, Michel; Le Brün, Jean; Poullet, Yves; Van Wymeersch, Charles, Les lettres de patronage, FEDUCI - Broche, París, 1984.

Block, K.; Steiner, J., "Comfort letters. Casual drafting can turn one into a guarantee”, New York Law Journal, 2004, Vol. 231, nº 13.

BRUNO, Giovanni, Le lettere di patronage nel rapporti economici, Liguori, Nápoles, 2004.

Cabrillac, Michel; Mouly, Christian, Droit des sûretés, Litec, París, $1997,4^{\text {a }}$ ed.

CAPrile Biermann, Bruno, "La reforma al derecho de las cauciones en Francia: perspectivas para un devenir en Chile", en Guzmán Brito, A. (editor), Estudios de derecho civil III, Legal Publishing, Santiago, 2008, pp. 531-565.

Chaparro Navarrete, Patricio, "Acerca de las operaciones bancarias y notas sobre 'securitización' o titulización de créditos (revisitada); bonos subordinados; 'comfort letters' y cartas de crédito 'standby", Gaceta Jurídica, 2001, no 248, pp. 102-109.

Carrasco Perera, Ángel, "Sentencia de 30 junio 2005: Cartas de patrocinio. Obligaciones resultantes de las declaraciones de titularidad sobre el capital de la filial y de apoyo financiero en caso de insolvencia", Cuadernos Civitas de Jurisprudencia Civil, 2006, nº 71, pp. 895-915.

Corral Talciani, Hernán, La 'cláusula penal'. Función y eficacia del contrato penal en el derecho chileno, Editorial Jurídica de Chile, Santiago, 2013.

De Castro Martín, José L., Las cartas de patrocinio, Cuadernos del Consejo General del Poder Judicial, Madrid, 1994.

Diago Diago, Ma. del Pilar, Las cartas de patrocinio en los negocios internacionales. Estudio jurídico, Thomson Reuters/Aranzadi, Cizur Menor, 2012.

Domínguez Pérez, Eva M., "Problemática de las cartas de patrocinio. Comentarios a algunos recientes pronunciamientos jurisprudenciales", Revista Crítica de Derecho Inmobiliario 2006, nº 694, pp. 782-795.

Elizalde Ibarbia, Francisco, El contenido del contrato, Thomson Reuters-Aranzadi, Cizur Menor, 2015. 
Enneccerus, Ludwig, Derecho de las obligaciones (trad. de B. Pérez González y J. Alguer), Bosch, Buenos Aires, 1948, T. II.

García VÁsquez, Diego, "Garantías independientes y cartas de patrocinio: las mejores alternativas para el comercio internacional”, Revist@, e-Mercatoria (U. Externado Colombia) 2006, 5-1, 16 pp.

GILIKER, Paula, "Taking comfort in certainty: to enforce or not to enforce the letter of comfort", Lloyd's Maritime and Commercial Law Quarterly 2004, $\mathrm{n}^{\circ} 2$, pp. 219-233.

MAzEAud, Vincent, L'obligation de couverture, IRJS, París, 2010.

Messineo, Francesco, Doctrina general del contrato (trad. R. O. Fontanarrosa, S. Sentis Melendo y M. Volterra), Ediciones Jurídicas EuropaAmérica, Buenos Aires, 1986, T. I.

Montero IgLesis, Marcelo, "Notas sobre el impacto de la formación del consentimiento en la interpretación del contrato entre partes sofisticadas", en De la Maza G., Iñigo (Editor), Cuadernos de análisis jurídico. Colección derecho privado, III: Temas de contratos, Ediciones Universidad Diego Portales, Santiago, 2011, pp. 115-129.

NetTer, Emmanuel, Les garanties indemnitaires, Presses Universitaires d'Aix-Marseille, Aix-Marseille, 2014.

Peñallillo Arévalo, Daniel, Obligaciones. Teoría general y clasificaciones. La resolución por incumplimiento, Editorial Jurídica de Chile, Santiago, 2003.

Perchinunno, Maria Colomba, "Il danno dell'affidamento sucitato dalla lettera di patronage", Contratto e Impresa, 2006, n 3 pp. 611-625.

Prado Lavín, Cristóbal, La carta de patrocinio, Memoria para optar al grado de Licenciado en Ciencias Jurídicas y Sociales, Universidad de Chile. Santiago, 1994.

PugA, Juana, Cómo hablamos cuando hablamos. La atenuación en el castellano de Chile, Ceibo, Santiago, 2014.

Puig Brutau, José, Fundamentos de derecho civil, II-2, Bosch, Barcelona, 1956.

SaCasas, Rene; WiESner, Don, "Comfort letters: the legal and business implications", Banking Law Journal, 1987, n³ 313, pp. 313-338.

SÁnchez-Calero Guilarte, Juan, "Valor jurídico de las cartas de garantía o cartas de patrocinio", en Sánchez Calero, Fernando; SánchezCalero G., Juan (editores), Comentarios a jurisprudencia de derecho bancario y cambiario, Centro de documentación y bursátil, Madrid, 1993, I, pp. 543-572.

SÁnchez-Calero Guilarte, Juan, El contrato autónomo de garantía. Las 
garantías a primera demanda, Centro de documentación bancaria y bursátil, Madrid, 1995.

Serrano Herrera, Claudia, "La legitimación para el pago de un tercero", Revista de Derecho de la Pontificia Universidad Católica de Valparaíso, 2011, Vol. XXXVII, pp. 137-211.

SuÁrez GonzÁlez, Carlos, Las declaraciones de patrocinio. Estudio sobre las denominadas "cartas de confort», La Ley, Madrid, 1994.

TAPia Rodríguez, Mauricio, "Noción de garantía”, en: Tapia Rodríguez, M.; Gaitán Martínez, José A.; Juricic Cerda, Daniel; Salah Abusleme, María A.; Mantilla Espinosa, Fabricio (Directores), Estudios sobre garantías reales y personales. Libro homenaje al Profesor Manuel Somarriva Undurraga, Editorial Jurídica de Chile, Santiago, 2009, I, pp. 21-28.

Valenzuela Garach, Fernando, "La "seriedad" de las llamadas cartas de patrocinio", Revista de Derecho Mercantil, 1987, n 185-186 pp. 347-427.

Vidal Olivares, Álvaro, "La construcción de la regla contractual en el derecho civil de los contratos", Revista de Derecho de la Pontificia Universidad Católica de Valparaíso 2000, Vol. XXI, pp. 209-227. 